\title{
Oxybutynin extended release for the management of overactive bladder: a clinical review
}

This article was published in the following Dove Press journal:

Drug Design, Development and Therapy

22 May 2009

Number of times this article has been viewed

\section{AM Arisco \\ EK Brantly \\ SR Kraus \\ University of Texas Health Science Center at San Antonio, Department of Urology, San Antonio, Texas, USA}

Correspondence: Stephen R Kraus University of Texas Health Science Center at San Antonio, Department of Urology, 7703 Floyd Curl Drive, MC, 7845, San Antonio, Texas 78229, USA

$\mathrm{Tel}+\mathrm{I}(2 \mathrm{I} 0)$ 567-5676

$\mathrm{Fax}+\mathrm{I}(210) 567-6868$

Email krauss@uthscsa.edu

\begin{abstract}
Overactive bladder $(\mathrm{OAB})$ is a common condition which negatively impacts the quality of life of afflicted patients. This can result in alterations in social interactions at home, in the workplace and in the community, often leading to depression and poor self esteem as well as loss of productivity. Traditional mainstays of treatment include both behavioral therapy and pharmacotherapy. Oxybutynin immediate release (IR) represents the first such medication approved by the FDA specifically for treatment of OAB in 1975. Nevertheless, bothersome side effects in addition to thrice daily dosing often led to treatment cessation which raised the question that patients may actually prefer to live with their OAB symptoms rather than incur side effects or complex dosing schemes. Pharmacological advances ultimately led to development of a long-acting formulation of oxybutynin in the form of oxybutynin extended release (ER) with the hope that this drug would maintain efficacy while decreasing bothersome side effects and improve compliance with the convenience of once daily dosing regimen. This paper will review the major clinical studies involving oxybutynin ER as well as its role in different patient populations and potential concerns with its use.
\end{abstract}

Keywords: overactive bladder, urinary urge incontinence, antimuscarinic, oxybutynin

\section{Introduction}

The International Continence Society defines overactive bladder (OAB) as: "Urgency, with or without urge incontinence, usually with frequency and nocturia in the absence of infection or any other proven causative pathology." Thus the OAB population includes both patients with urge incontinence (OAB wet) as well as without urge incontinence (OAB dry). Indeed, the incidence of $\mathrm{OAB}$ dry has been reported at $66 \%$ of OAB patients while $33 \%$ have "OAB wet" and suffer from leakage. ${ }^{2}$ With prevalence rates similar to those of asthma and chronic bronchitis, the burden of this disease is enormous and presents great cost to society. ${ }^{3}$ The National Overactive Bladder Evaluation (NOBLE) Program was a large scale, well designed epidemiological study which reported the prevalence of OAB in the US at approximately $16 \%$ with the distribution between men and women being roughly equal and with the prevalence mounting with increasing age. ${ }^{3}$ Similar results were seen in epidemiological studies in Europe with prevalence rates of $\mathrm{OAB}$ in the $12 \%$ to $17 \%$ range. $^{4}$

The pathophysiology of $\mathrm{OAB}$ is not completely understood and likely there are multiple pathways leading to the end disease state. Normal bladder storage and micturition function requires precise neurologic and muscular coordination; possible alterations at the myogenic, mucosal and neurogenic levels may contribute to the condition. While caus- 
ative myogenic and mucosal alterations would take place at the end organ (bladder and urethra), adverse changes in bladder innervations may occur at the peripheral or central level. In such neurogenic theories, alterations in the neurologic pathways that normally provide tonic inhibition of detrusor contractions may account for the disease state. ${ }^{5}$ Alternatively, sensory nerve endings in the bladder may become hypersensitive, resulting in detrusor overactivity. ${ }^{5}$ Indeed, research studying the role of the urothelium in normal and abnormal micturitional states has advanced dramatically and shaped the field of OAB. It has long been understood that the autonomic nervous system plays a critical role in micturition. The sacral parasympathetic outflow provides excitatory input to the bladder via the pelvic nerve, which results in detrusor contraction. Bladder ganglia cells excite detrusor smooth muscle with release of both cholinergic neurotransmitter in the form of acetylcholine and also non-cholinergic, non-adrenergic neurotransmitters. ${ }^{5}$ Acetylcholine activates muscarinic receptors on the detrusor smooth muscle and is considered a key neurotransmitter for detrusor function. There are 5 distinct subtypes of the muscarinic receptor throughout the body (M1-M5), the M2 and M3 sub-types predominating in the bladder. Although the density of $\mathrm{M} 2$ receptor is higher than the M3 receptor in the human bladder, M3 is thought to be more important in the manifestation of detrusor contractions. ${ }^{6}$ Given this basic understanding of neuroanatomy, it is not surprising that muscarinic cholinergic receptors became early therapeutic targets in $\mathrm{OAB}$ treatment.

Oxybutynin immediate release (IR) represents the first such medication approved by the FDA specifically for the treatment of OAB in $1975 .^{7}$ It was originally investigated in the 1960s for the potential treatment of gastrointestinal hypermotility. Researchers incidentally discovered its usefulness as an agent for $\mathrm{OAB}$ and it has been since widely used for decades. In addition to its anticholinergics effects oxybutynin also shows some in vitro activity as a direct smooth muscle relaxant ${ }^{8}$ and early in vitro studies on rabbit detrusor also noted moderate local anesthetic action. ${ }^{9}$ Clinical efficacy for treatment of OAB symptoms was well documented in the 1990s. ${ }^{10}$ Despite proven efficacy, oxybutynin IR shows some major shortcomings as a therapeutic drug, namely high side effects, some so bothersome that some patients prefer to discontinue treatment and endure the disease itself rather than deal with the side effects. Lawrence et al showed a 6-month treatment adherence rate of only $32 \%$ in a retrospective analysis 515 patients prescribed oxybutynin IR in a pharmacy claims database. ${ }^{11}$ These pitfalls stem from fact that oxybutynin has a relatively nonspecific affinity for all of the various muscarinic receptors which are widespread throughout the human body. In addition to muscarinic receptors in the bladder, oxybutynin has particular affinity for muscarinic receptors in the central nervous system (CNS), gastrointestinal (GI) tract, parotid gland and eye which may account for troublesome cognitive impairment, constipation, dry mouth and difficulty with papillary accommodation. Of these, dry mouth appears to be most prominent, occurring in up to $80 \%$ of patients taking oxybutynin. ${ }^{12}$ Beyond bother, decreased salivation may predispose to oral infections and dental caries as well as inhibit proper mastication and swallowing, particularly in the elderly. ${ }^{13,14}$

Given the limitations of oxybutynin IR, it comes as no surprise that alternative agents would be explored in the hopes that tolerability could be improved while maintaining efficacy in the treatment of OAB. Other antimuscarinics such as propantheline, methantheline, emepronium, dicyclomine, and terodiline were once employed as alternative OAB treatment options as they were perceived to be more tolerable, however they were eventually abandoned due to either lack of efficacy and/ or poor tolerability. ${ }^{15,16}$ Currently, there are five different antimuscarinic drug formulations on the market for treatment of $\mathrm{OAB}$ in addition to oxybutynin. Tolterodine, propiverine, trospium, darifenacin and solifenacin all possess differing pharmacokinetic properties relating to organ and receptor subtype selectivities as well as structural differences. In addition, a separate strategy for changing the side effect profile of oxybutynin was employed by using an extended release (ER) formulation. In addition, a patch formulation of oxybutynin was developed in hopes that tolerability could be improved through of use of a different delivery system which altered drug metabolism and lengthened the drug dosing interval. An oxybutynin gel formulation was recently introduced into the US market with similar aims. In this article we focus our attention on oxybutynin ER formulation likewise meant to simplify drug dosing and improve on the side effect profile of the older oxybutynin IR.

\section{History of oxybutynin ER}

Oxybutynin ER came to market in the United States in $1998^{17}$ with intent to improve upon tolerability, convenience and compliance while maintaining efficacy by offering once daily dosing. OROS oxybutynin chloride (oxybutynin ER, Ditropan $\mathrm{XL}^{\circledR}$ ) is an extended-release oral tablet formulation $\left(\mathrm{OROS}^{\circledR}\right.$ ) which utilizes osmotic pressure to deliver the drug at a controlled rate over 24 hours. The tablet itself consists of a semi-permeable membrane covering a drug layer which overlies an osmotically active "push" layer. In the GI tract, 
the absorption of water by this osmotically active layer results in the expulsion of the drug (which has likewise absorbed water forming a suspension) out a small opening in the membrane. Pharmacokinetic studies show that after the first dose of oxybutynin ER, plasma drug concentration rises for 6 hours and then maintains a constant concentration for up to 24 hours with steady state plasma concentrations achieved by day three of treatment. ${ }^{18}$ Normally, when absorbed in the upper GI tract, oxybutynin IR undergoes first pass metabolism by the cytochrome P450 system into its active metabolite $\mathrm{N}$-desethyloxybutynin (NDO). This may be particularly important as NDO has been proposed to be responsible for more dry mouth than oxybutynin itself. ${ }^{19}$ However, because the OROS system delays the release of oxybutynin in the ER formulation, it is thought that the parent drug is not biologically available until the tablet reaches the large intestine. By this point, the drug has bypassed the upper GI's first pass metabolism system and is left to be absorbed in the colon where conversion to NDO is less likely and absorption is mainly of the parent drug itself. Biologically inert components of the tablet including the tablet itself are ultimately eliminated in the feces.

\section{Early studies: extended release vs placebo and immediate release vs extended release}

Early studies compared the effects of oxybutynin ER to placebo. The drug did show at least $40 \%$ greater decrease in urinary urge incontinence versus placebo in a 6-week trial though the results are recorded in abstract form only. ${ }^{20}$ In an early industry sponsored study Anderson et al for the Ditropan Study Group enrolled 105 patients with urge incontinence into a randomized, double blind study of dose titration to compare the efficacy and safety of controlled and immediate release oxybutynin. They concluded that both groups shared a similar rate of reductions in urge incontinence and total incontinence episodes while the oxybutynin ER group reported significantly less dry mouth at $68 \%$ compared to $87 \%$ for any degree of complaint. ${ }^{21}$ Another study published in the year 2000 sought to compare the efficacy and safety of oxybutynin IR as well as to determine rates of dry mouth. The authors enrolled known anticholinergic responders with seven or more urge incontinence episodes per week into a dose escalation trial of the IR and ER drug forms starting at $5 \mathrm{mg}$ per day and increasing to $20 \mathrm{mg}$ per day as limited by intolerable side effects. They likewise found comparable rates of reduction in incontinence episodes with similar rates of dose-dependent dry mouth, but moderate to severe dry mouth was significantly less prominent in the group receiving oxybutynin ER. Stratified by dosage, the greatest differences were at the $10 \mathrm{mg}$ per day (8.5\% for the ER group vs $25.6 \%$ for the IR group) and $15 \mathrm{mg}$ per day doses (19.4\% for the ER group vs $38.9 \%$ for the IR group) groups. ${ }^{22}$ Nevertheless, the early data on direct comparisons between oxybutynin IR and ER remain limited by trial design shortcomings including studying enriched populations such as known responders and reporting results on a "completer" basis. Some are reported only in abstract form at meetings and many are industry sponsored, thus limiting the ability to make evidence-ased conclusions of the two drug formulations.

In 2005 Dmochowski reported on the efficacy and safety of "individualized" doses of oxybutynin ER for urinary incontinence. ${ }^{23}$ His group combined data from three flexibledosing studies of patients with urge urinary incontinence or mixed incontinence; two of the data sets used were from trials completed in the late 1990s on ER versus IR oxybutynin while the third was from a study published in 1999 by the Ditropan XL Study Group on "evaluation of a new once-daily formulation of oxybutynin for the treatment of urge urinary incontinence." ${ }^{19,20,24}$ A total of 420 patients combined were assigned to treatment with oxybutynin ER. In the combined dataset, 420 patients were assigned to treatment with oxybutynin ER. Treatment began with $5 \mathrm{mg}$ daily of oxybutynin ER and was increased in 5-mg increments at intervals of approximately 1 week until the patient either achieved complete continence or experienced intolerable side effects. Maximum dose was limited to $30 \mathrm{mg}$ each day. The patients remained on maxiumum dose for 2 to 12 weeks according to which study they were participating in. Of these patients, some $14 \%$ had withdrawn prior to completion of their respective trial (some $6.7 \%$ due to adverse events), leaving 368 on drug at the end of the study periods. From the pooled data, $40 \%$ of these patients achieved total dryness with $80 \%$ sustaining $70 \%$ or better improvement in incontinence at their respective doses. Dry mouth was the most prevalent adverse event, but some $3 / 4$ of the studied patients experienced only mild or no dry mouth at all. The authors made note of the fact that $7 \%$ of the patients selected the dose of $30 \mathrm{mg}$ per day with only slightly higher rates of dry mouth and similar rates of treatment discontinuation due to adverse events as subjects at lower daily doses. The authors freely acknowledge the limitations of post-hoc analysis of pooled data from studies that employed varying methodologies. In addition they recognize that the three studies each contained some of the previously discussed study design flaws common to early 


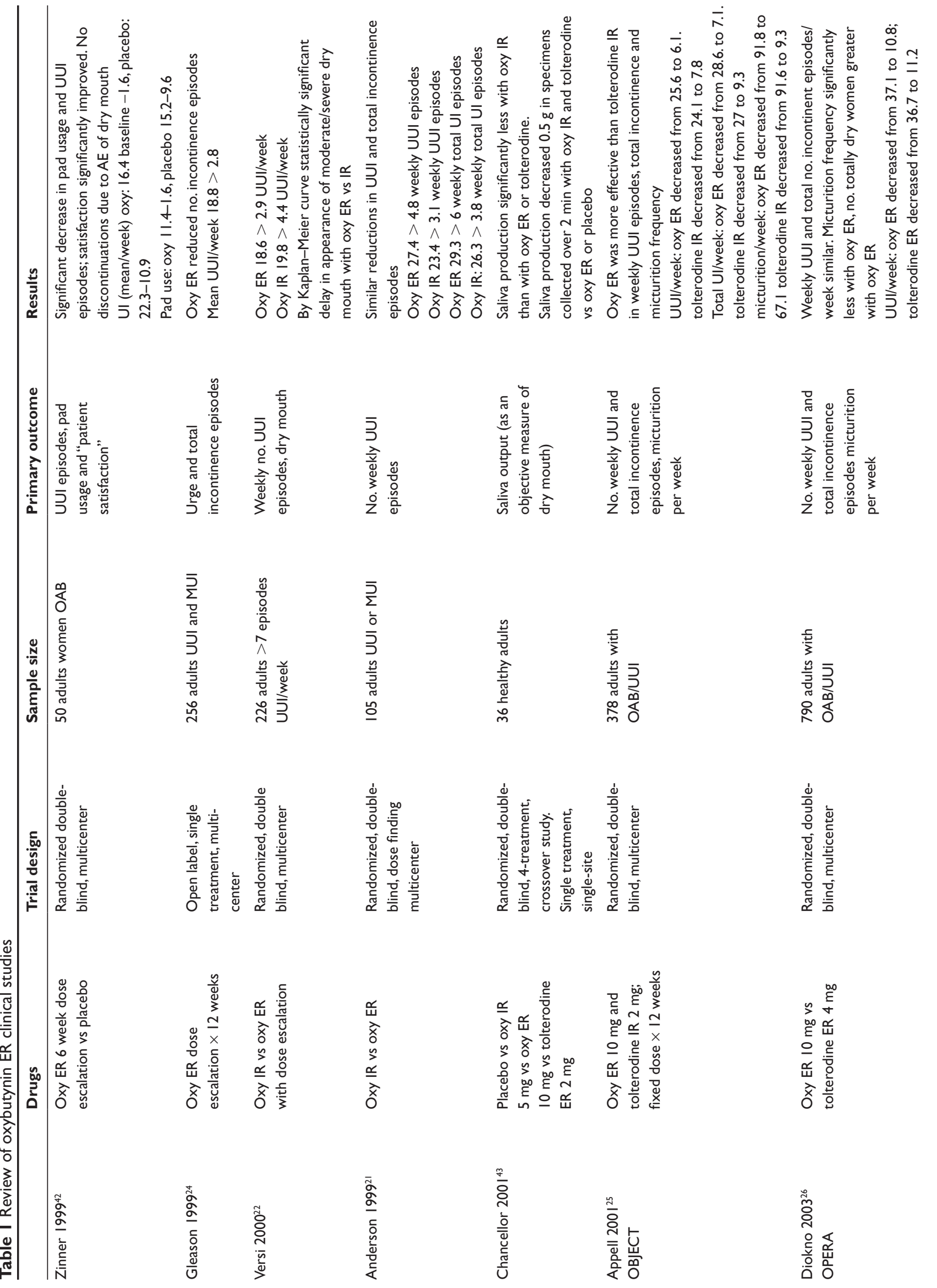



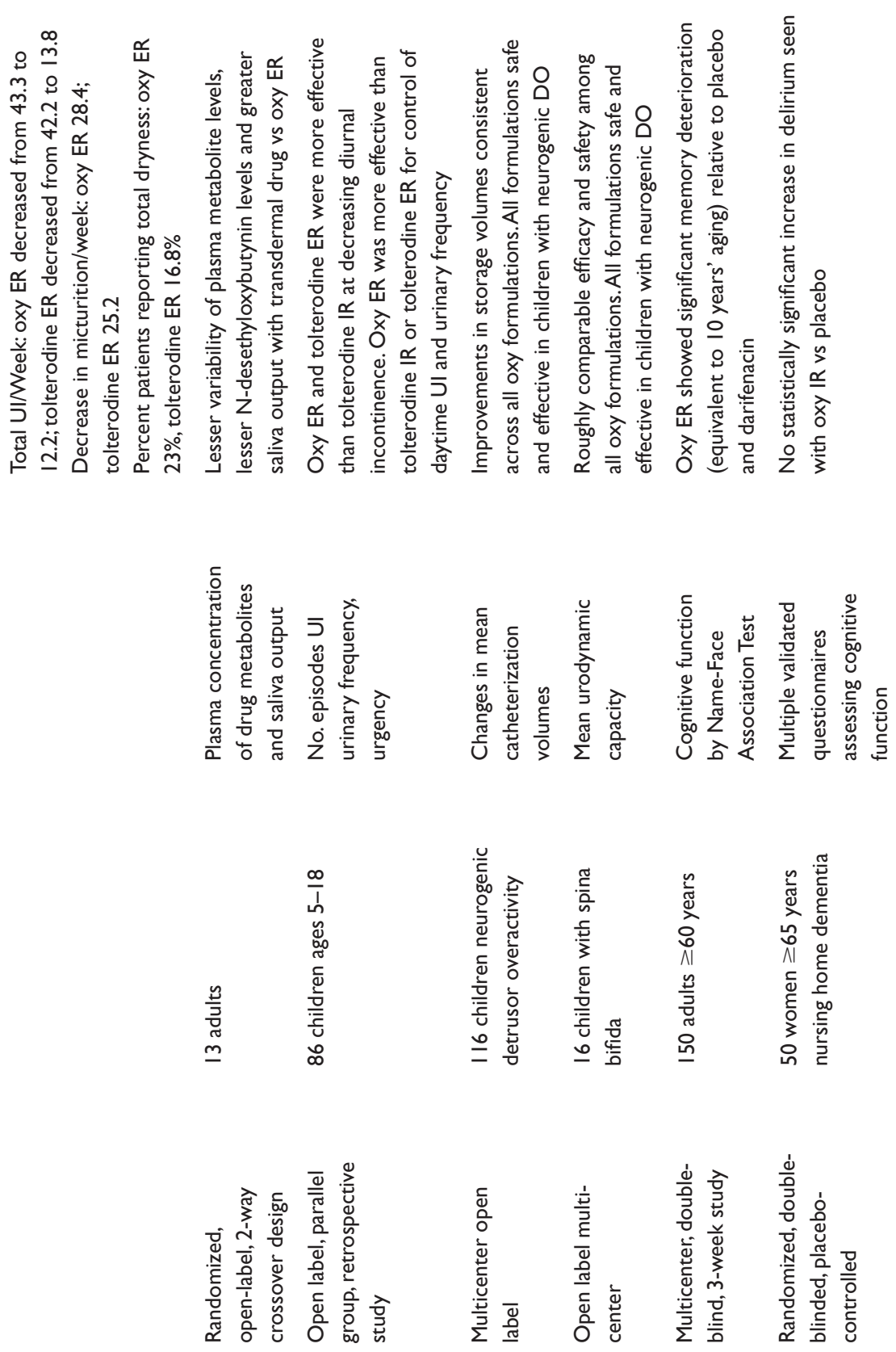

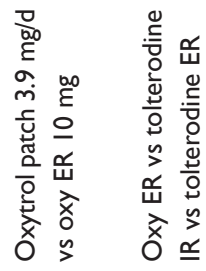

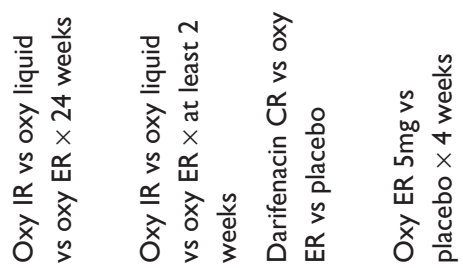

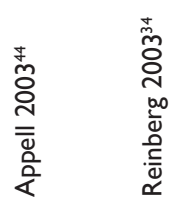

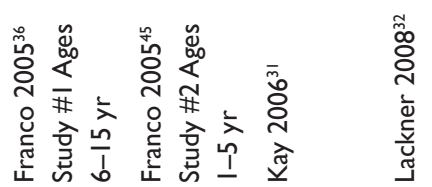

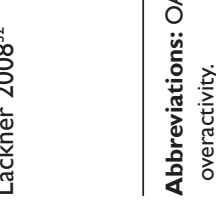


studies of oxybutynin ER versus IR, further weakening conclusions drawn in this paper. ${ }^{21}$

\section{Oxybutynin ER vs other OAB medications}

The next round of clinical trials involving oxybutynin mainly focused on comparison studies to other OAB medications. Two large, multi-center, prospective, randomized clinical trials comparing oxybutynin ER and tolterodine tartrate in $\mathrm{OAB}$ patients stand out for their sound methodology and power relative to all other clinical trials employing oxybutynin ER: the Overactive Bladder: Judging Effective Control and Treatment (OBJECT) Study ${ }^{25}$ and the Overactive Bladder: Performance of Extended Release Agents (OPERA) trial. ${ }^{26}$

The OBJECT study was conducted between March and October 2000 at 37 US study sites with the objective to compare the efficacy and tolerability of fixed dose extendedrelease oxybutynin and tolterodine tartrate at 12 weeks. The study enrolled and randomized 315 women and 63 men with overactive bladder who received either oxybutynin ER $10 \mathrm{mg}$ daily or tolterodine tartrate $2 \mathrm{mg}$ q 12 hours in a double-blind, double-dummy fashion. Trial completion was accomplished by 276 women and 56 men while a total 46 discontinued early, 29 because of adverse events (14 in the oxybutynin ER and 15 in the tolterodine group). Efficacy was assessed using self (diary) reported incontinence episodes as a primary outcome measure. The diaries documented number of voids as well as number and nature of incontinence episodes. Study findings included similar tolerability and discontinuation rates as well as similar adverse event rates for both drugs. In the OBJECT Study, oxybutynin ER proved significantly more effective than tolterodine in reducing the mean number of weekly urge incontinence episodes at end of study as well as total incontinence episodes and total urinary frequency. Urge incontinence episodes improved from $25.6 \pm 14.7$ to $6.1 \pm 9.7$ for oxybutynin ER and $24.1 \pm 14.5$ to $7.8 \pm 11.1$ for tolterodine. Total number of incontinence episodes per week decreased from $28.6 \pm 17.9$ to $7.1 \pm 12$ for oxybutynin ER and from $27 \pm 17$ to $9.3 \pm 13.4$ for tolterodine. Micturitions per week decreased from $91.8 \pm 22.6$ to $67.1 \pm 22.1$ for oxybutynin ER and from $91.6 \pm 20.2$ to $71.5 \pm 20.5$ for tolterodine. Both drugs significantly improved all studied outcome parameters. The authors made note of the limited applicability of 12 week results with regards to a chronic condition such as OAB. They also noted that the study population was selected by specialists rather than primary care physicians who treat most $\mathrm{OAB}$ and that study population was not racially diverse, though this is a common limitation in most OAB studies. It should be noted that OBJECT compared once daily oxybutynin ER to twice daily tolterodine tartrate, though this formulation of tolterodine has essentially been replaced in most cases by the once daily formulation of tolterodine which is expected to improve patient compliance. Regardless, OBJECT did compare oxybutynin ER with the most widely prescribed non-generic anticholinergic medication at that time in a blinded head to head randomized clinical trial in the US. ${ }^{23}$

It must be noted that the OBJECT study was funded by ALZA Corporation in Mountain View, California, a biopharmaceutical company with specialization in drug delivery systems and developer of the OROS drug delivery system. The authors include advisors, investigators and speakers for ALZA Corporation as well as one employee stockholder of ALZA Corporation.

The second large multicenter trial, OPERA, was likewise funded by the ALZA Corporation as well as Ortho-McNeil Pharmaceutical in Raritan, NJ, makers of oxybutynin ER. OPERA authors likewise disclosed relationships including: medical consultant, investigator, advisor as well as an employee and stockholder of Ortho-McNeil and an employee and stockholder of AZLA.

The OPERA Trial sought to compare the efficacy and tolerability of extended-release formulations of both oxybutynin chloride and tolterodine tartrate in women with overactive bladder. The trial ran from November 2000 to October 2001 and pitted oxybutynin ER head to head with the most prescribed once daily anticholinergic in a prospective, randomized, double-blind study conducted at 71 US centers. US women aged 18 years or older who documented 21 to 60 episodes of urinary urge incontinence per week and an average of 10 or more voids per 24 hours were recruited. A total of 790 women were randomized to receive either $10 \mathrm{mg}$ of oxybutynin ER or $4 \mathrm{mg}$ of tolterodine ER per day. Randomized groups were similar in both demographics and severity of OAB while prior treatment for OAB was not an exclusion criteria. Patients kept 24-hour voiding diaries at baseline and during weeks 2, 4, 8 and 12 of treatment. Outcome measures were reduction from baseline in the number of urinary urge incontinent episodes/week, weekly total incontinence episodes and weekly micturition frequency numbers. A similar number of patients completed the study in both groups ( $87 \%$ for the oxybutynin ER group versus $89 \%$ for the tolterodine ER group.) Likewise, rates of discontinuation due to adverse events were essentially equal with 20 oxybutynin patients and 19 tolterodine ER patients. 
There was no statistical difference in the number of weekly urge incontinent episodes at the end of study for the competing groups. After 12 weeks of treatment, the oxybutynin ER group saw a reduction from a mean of 37.1 to 10.8 urge incontinent episodes per week while the tolterodine ER group dropped from 36.7 to 11.2. The oxybutynin ER group performed slightly for reducing total mean number of weekly incontinent episodes and weekly micturition frequency. This was statistically significant for the number of micturition episodes per week. For total incontinent episodes per week, the oxybutynin group went from 43.4 to 12.3 and the tolterodine group from 42.4 to 13.8 . Total decrease in mean number of voids per week was 28.4 for the oxybutynin group versus 25.2 for the tolterodine group; respective means were 66.4 and 71.7 at the end of 12 weeks treatment. Slightly more patients in the oxybutynin ER group reported no incontinence episodes in their final diary versus the tolterodine ER group at $23 \%$ versus $16.8 \%$ completely dry. Dry mouth was more common in the oxybutynin ER group at $29.7 \%$ versus $22.3 \%$ in the tolterodine group; while statistically significant, the majority of the dry mouth effects were categorized as mild (93\% of oxybutynin ER participants and $95 \%$ of tolterodine ER participants. ${ }^{24}$

Overall, the OPERA study shows oxybutynin ER to have modestly greater efficacy than ER tolterodine at its most commonly prescribed dose. The authors point out that the flexible dosing allowed for oxybutynin provides a wider range of FDA approved dosages allowing individuals to balance their respective efficacy and tolerability without turning to off label dosages as would be required with tolterodine ER of $4 \mathrm{mg}$ daily. One obvious limitation of the OPERA study is its study population of women only. While women do constitute the majority of patients presenting with complaints of overactive bladder, the condition is certainly not limited to women. Some epidemiological studies would argue that the prevalence in men is nearly equal. ${ }^{3}$

In 2006, Anderson et al published a post hoc analysis of data from the OPERA trial specifically comparing the efficacy and tolerability of oxybutynin ER and tolterodine ER in women with or without prior anticholinergic treatment for OAB. They found that oxybutynin ER was significantly more effective in reducing micturition frequency by week 12 among the population of patients with prior anti-cholinergic treatment experience. Likewise in this particular subgroup, the participants taking oxybutynin ER reported a statistically significant greater chance of being incontinence free and they had a greater reduction in number of urge incontinence episodes. In contrast, the anticholinergic-naive group showed statistically equal efficacy for all study parameters with the exception of average number of micturitions per week at study completion; this parameter favored the participants taking oxybutynin ER. Dry mouth was more common in the oxybutynin ER study participants, but only in the group with history of prior anticholinergic treatment. ${ }^{27}$

\section{Special populations and other trials}

Several clinical trials address the use of oxybutynin ER in special populations, including the elderly, children, and neurogenic bladder. Interestingly, while the concept that OAB may contribute to male lower urinary tract symptoms has become more widely accepted ${ }^{28}$ we were unable to identify any studies in the literature focusing on oxybutynin ER in the male subpopulation. Oxybutynin ER is considered: "Pregnancy Catetory B," reproduction studies in the mouse, rat, hamster and rabbit showing no definite evidence of impaired fertility or harm to animal fetus. According to the manufacturer's package insert: "The safety of Ditropan XL administration to women who are or may become pregnant has not been established. Therefore Ditropan XL should not be given to pregnant women unless, in the judgement of the physician, the probable clinical benefits outweigh the possible hazards." It is unlikely that studies of oxybutynin in pregnant women will ever be undertaken.

The elderly represent a special population in OAB treatment particularly related to risk of negative effects on the CNS such as cognitive impairment and memory problems. They tend to be at risk for poly-pharmacy, often taking a variety of medicines besides anticholinergics which may also have adverse effects on the CNS. As the number of medications use increases, so does the risk to the older patient including problems with compliance as well as potential drug-drug interactions which can cause adverse events or alter drug efficacy. ${ }^{29}$ Older patients are at risk for falls and sleep disturbances, and they often already suffer from dry mouth, dry eye, and vision problems as well as GI motility problems including constipation. ${ }^{30}$

Kay et al studied the differential effects oxybutynin ER versus the drug darifenacin on memory in older patients. In a multicenter, double blind study, 150 healthy individuals over the age of 60 with $\mathrm{OAB}$ were randomized to receive oxybutynin ER, darifenacin or placebo. Initial dose for oxybutynin ER was $10 \mathrm{mg}$ daily, and increases in 5-mg increments was permitted up to $20 \mathrm{mg}$ by the end of this 3-week study. Initial dose for darifenacin was $7.5 \mathrm{mg}$ each day for 2 weeks, with permitted increase to $15 \mathrm{mg}$ each day for the final week. Primary outcome was the effect of each antimuscarinic 
versus placebo at 3 weeks on recent memory as measured by the delayed recall Name-Face Association Test. Secondary end points included delayed recall on the First-Last Name Association Test and the Misplaced Objects test. Results of this study showed that oxybutynin ER caused significant memory deterioration, while darifenacin did not cause memory changes significantly different from placebo. While oxybutynin ER may be FDA approved to $30 \mathrm{mg}$ daily dose, the most commonly prescribed dosage is $10 \mathrm{mg}$ daily which is the same dose selected for OBJECT and OPERA trials. Despite this potential dosage mismatch, interval evaluation of study subjects does show a drop in measured cognitive function in the oxybutynin ER group after one week even at $10 \mathrm{mg}$ daily. Despite the short duration of the study, it does show that older patients with pharmacological steady state plasma levels of oxybutynin ER may have an increased risk of impaired cognitive function relative to those in steady state taking darifenacin. ${ }^{31}$

Contrary to the relatively high dose oxybutynin ER used in previous study, Lackner reported a randomized, placebocontrolled trial of the cognitive effect, safety and tolerability of $5 \mathrm{mg}$ daily dosage of oxybutynin ER in a population of cognitively impaired nursing home residents with urge incontinence. The authors cite that $\mathrm{OAB}$ is undertreated in this population due to the fear that the frail older patient is more susceptible to anticholinergic associated adverse reactions. They note the lack of studies to document safety and efficacy of anticholinergics in the frail elderly population despite the high prevalence of urinary urge incontinence in particular. In this trial, 50 women aged 65 and older with urge incontinence and documented cognitive impairment were randomized to oxybutynin ER versus placebo and followed closely for 4 weeks. Primary outcome measures included the Confusion Assessment Method (CAM,) an accepted, validated and widely used diagnostic algorithm to measure cognitive function. Changes in CAM score from baseline were the primary outcome with presence or absence of delirium as determined by the CAM. Other secondary endpoints were further standardized measurements of cognition. In short, the study showed that oxybutynin ER $5 \mathrm{mg}$ daily was well tolerated in elderly female nursing home patients with mild to severe dementia. There was no significant impairment in cognitive function in the treatment group by any measured outcome at any measured point in the study. There were no more withdrawals in the treatment versus placebo groups nor was there any difference in adverse events. Forty seven participants completed the study, 96\% on drug versus $92 \%$ receiving placebo. Rates of agitation and falls were equal with $54 \%$ of the participants in both groups experiencing at least one fall during the months preceding, including and following the trial. Study limitations include the short duration, homogenous Caucasian female population as well as lack of information about efficacy at this dosage. ${ }^{32}$ However, these results do contradict the guidelines of the American Neurological Association, the American Psychiatric Association and the Beers Criteria for Potentially Inappropriate Medication Use in Older Adults ${ }^{33}$ and conclusions about their use in this population remain guarded.

CNS side effects do represent a cause of potential severe consequences in the elderly in particular. Current US prescribing information applying to all forms of oxybutynin states under precautions: "A variety of CNS effects have been reported including hallucinations, agitation, confusion and somnolence. Patients should be monitored for signs of anticholinergic CNS effects, particularly in the first few months after beginning treatment or increasing the dose." It also cautions that the drug "should be used with caution in patients with pre-existing dementia treated with cholinesterase inhibitors due to risk of aggravation of symptoms" and that the drug "should be used with caution in the frail elderly."

Children represent another highly unique "special" population to consider when considering drug therapy. Drug treatment of neurologically intact children with $\mathrm{OAB}$ type symptoms generally focuses on incontinence, which can, in older children have marked effects on the child's social and psychological development and well being in addition to causing great stress and anxiety in parents. Beyond behavioral therapy and biofeedback, clinicians, parents and patients often wish to turn to drug therapy to treat $\mathrm{OAB}$. While studies on $\mathrm{OAB}$ drugs in adults are limited and conflicting, there are, simply put, very few studies in children. Only one non-randomized clinical study was identified investigating therapeutic efficacy and tolerability of oxybutynin ER in children. The authors identified 86 girls and 46 boys between the ages of 5 and 18 years of age who were referred to a pediatric urology clinic with diurnal urinary incontinence and $\mathrm{OAB}$ symptoms including urinary frequency, urgency, posturing associated with urge and/or spontaneous urinary incontinence. These children were arbitrarily assigned to receive tolterodine IR, tolterodine ER or oxybutynin ER based primarily on the formulary restrictions of their health care plans. Medications were started at the lowest dose available in non-liquid form (tolterodine IR and ER at $2 \mathrm{mg}$, oxybutynin ER $2 \mathrm{mg}$ ) and titrated according to response and tolerability. After thorough baseline 
evaluations, study nurses assessed efficacy by voiding diary and side effects on the basis of direct questioning to parents and patients. Validated instruments were not used and it appears that assessments did not occur at set, prescribed points in time. In 2003 the authors reported their retrospective analysis citing that all medications appeared well tolerated and that the ER formulations of both oxybutynin and tolterodine were significantly more effective than IR tolterodine. Oxybutynin ER was again significantly more effective than either formulation of tolterodine for control of daytime urinary incontinence and micturition frequency. ${ }^{34}$ While this non-randomized, non-blinded retrospective study using non-validated instruments contains serious flaws, it nevertheless represents the very small amount of literature devoted to use of oxybutynin ER in children and suggests that the use of this type of medication is safe and effective in children and that oxybutynin ER is at least as effective as either formulation of tolterodine.

One other study focused on the use of oxybutynin ER in children with neurogenic bladder (NGB). This is a distinct and important subset of patients who frequently require aggressive management of bladder issues to maximize social functionality as well as to protect renal function. While published studies as early as 1977 address the use of oxybutynin IR in this population, very little is available regarding oxybutynin ER in children with NGB ${ }^{35}$ Interestingly, no studies were identified which reported specifically on use of oxybutynin ER in adults with neurogenic bladder. Franco et al reported on use of three different formulations of oxybutynin in children aged 6-15 years of age who performed clean intermittent catheterization (CIC) and who had documented neurogenic detrusor overactivity at 24 different centers in the US and Europe. Sixty one patients received oxybutynin ER while 28 received oxybutynin IR and 30 were treated with oxybutynin syrup. Efficacy and tolerability were assessed at 24 weeks. Improvement of urodynamic parameters was seen in all treatment arms as well as increased continence. Likewise all three drug formulations were well tolerated and no patient discontinued treatment due to adverse events related to oxybutynin. In contrast to other studies, constipation represented the most frequently reported adverse event in this population while dry mouth is not even listed as occurring at $5 \% .{ }^{36}$ Despite flaws, this report does provide some evidence for tolerability of oxybutynin ER in this small but important patient population.

Finally we consider the issue of cost related to $\mathrm{OAB}$ and oxybutynin ER. First, one must understand the staggering financial cost of $\mathrm{OAB}$ in modern society; estimates of dollars spent annually in the US alone run to US\$12 billion. ${ }^{37}$ While non-pharmacological treatment methods may be employed, anticholinergic medications represent the mainstay of treatment for $\mathrm{OAB}$ and drug costs contribute considerably to the overall burden of cost related to OAB. However, some studies do indicate that drug therapy for OAB may be associated with decreased utilization of other healthcare resources resulting in cost savings elsewhere; ${ }^{38}$ naturally, the cost of therapeutic medication for OAB may offset these net savings. Considerable literature in the managed care and pharmacoeconomics literature is devoted to these issues including evaluations of oxybutynin ER as a therapeutic choice for $\mathrm{OAB}$. The economic modeling is quite complex and unique in each case due to the regional or geographic variation with myriads of variables affecting cost of treatment and cost of disease state. One European study sought to study the cost-effectiveness of long-term pharmacological management of urge urinary incontinence using IR oxybutynin and tolterodine as well as ER formulations of the two drugs in the United Kingdom. The study included estimated costs of incontinence products such as pads which are often paid out of pocket in the US and often overlooked. They concluded that tolterodine IR was less cost effective than the other three drug choices. ${ }^{39}$ In contrast, two large US retrospective studies designed to determine financial cost and benefit of treatment with ER formulations of oxybutynin versus tolterodine estimated healthcare costs based on reimbursement for services (hence only covered benefits) by using enormous patient databases related to US health insurers. ${ }^{40,41}$ Both studies found cost savings in total reimbursement costs over one year for patients treated with tolterodine ER versus oxybutynin ER.

\section{Conclusions}

Antimuscarinic agents remain a mainstay of therapy for the treatment of $\mathrm{OAB}$. While this medication class has proven efficacious for this condition, decreased tolerability due to antimuscarinic side effects remains a major problem limiting its acceptance. Oxybutynin has proven to be effective for the treatment of $\mathrm{OAB}$ however antimuscarinic side effects such as dry mouth and constipation often limit patients' compliance with it. The use of the OROS delayed release delivery system is an excellent example of how altering the delivery of the active agent can improve oxybutynin's tolerability while still maintaining its effectiveness. This transformation has allowed oxybutynin to remain a formidable treatment option for $\mathrm{OAB}$ despite the introduction of newer and more tissuespecific antimuscarinic agents. 
Oxybutynin ER has clearly demonstrated its applicability in the treatment of OAB and voiding dysfunction in the adult population. Oxybutynin IR has been widely used in the pediatric population for neurogenic bladder and voiding dysfunction though there are limited studies looking at the oxybutynin ER formulation in children. The use of oxybutynin in the elderly remains a concern and treatment dilemma. The incidence of $\mathrm{OAB}$ and urinary incontinence increases with age yet the use of oxybutynin in this population is cautioned due to concerns that older patients may have problems with increased side effects especially for CNS, memory and cognition. These concerns warrant further investigation.

\section{Disclosures}

The authors declare no conflicts of interest.

\section{References}

1. Abrams P, Cardozo L, Fall M, Griffiths D, Rosier P, Ulmsten U, et al. The standardisation of terminology of lower urinary tract function: report from the Standardisation Sub-committee of the International Continence Society. Neurourol Urodyn. 2002;21:167.

2. Stewart WF, Van Rooyen JB, Cundiff GW, et al. Prevalence and burden of overactive bladder in the United States. World J Urol. 2003; 20:327-336.

3. Brown JS, Nyberg LM, Kusek JW. Proceedings of the National Institute of Diabetes and Digestive and Kidney diseases international symposium on epidemiologic issues in urinary incontinence in women. Am JObstet Gynecol. 2003;188(6):S77-S88.

4. Irwin DE, Milsom I, Hunskaar S, et al. Population-based survey of urinary incontinence, overactive bladder, and other lower urinary tract symptoms in five countries: results of the EPIC study. Eur Urol. 2006;50:1306-1315.

5. de Groat WC. A neurologic basis for the overactive bladder. Urology. 1997;50(6A supp1):36-52.

6. Steers WD, Darifenacin: pharmacology and clinical usage. Urol Clin North Am. 2006;33(4):475-482.

7. Diokno A, Ingber M. Oxybutynin in detrusor overactivity. Urol Clin North Am. 2006;33(4):439-445.

8. Kachur JF, Peterson JS, Carter JP. RS enantiomers of oxybutynin: pharmacological effects in guinea pig bladder and intestine. J Pharmacol Exp Ther. 1988;247(3):867-872.

9. Fredericks CM, Green RL, Anderson GF. Comparative in vitro effects of imiprimine, oxybutynin and flavoxate on rabbit detrusor. Urology. 1978;12(4):487-491.

10. Hashimoto K, Ohnishi N, Esa A. Clinical Efficacy on oxybutynin on sensory urgency as compared with that on motor urgency. Urol Int. 1999;62(1):12-16.

11. Lawrence M, Guay DR, Benson SR, Anderson MJ. Immediate-release oxybutynin versus tolterodine in detrusor overactivity: a population analysis. Pharmacotherapy. 2000;20(4):470-475.

12. Yarker YE, Goa KL, Fitton A. Oxybutynin: A review of its pharmacodynamic and pharmacokinetic properties, and its therapeutic use in detrusor instability. Drugs Aging. 1995:6:243-262.

13. Narahi TO, Meurman JH, Ainamo A. Xerostoma and hyposalivation: causes consequences and treatment in the elderly. Drugs Aging. 1999;15(2):103-116.

14. Turner MD, Ship JA. Dry mouth and its effects on elderly people. J Am Dent Assoc. 2007;138:15S-20S.

15. Wall LL. The management of detrusor instability. Clin Obstet Gynecol. 1990;33:367-377.
16. Wein AJ. Pharmacologic options for the overactive bladder. Urology. 1998;51(Suppl.):43-47.

17. http://www.accessdata.fda.gov/Scripts/cder/DrugsatFDA/index.cfm

18. Goldenberg MM. An extended-release formulation of oxybutynin chloride for the treatment of overactive urinary bladder. Clin Ther. 1999; 21(4):634-642.

19. Waldeck K, Larsson B, Andersson KE. Comparison of oxybutynin and itsactive metabolite N-desethyloxybutynin in the human detrusor and parotid gland. J Urol. 1997;157:1093-1097.

20. Siddiqui, Perry CM, Scott LJ. Oxybutynin extended-release: a review of its use in the management of overactive bladder. Drugs. 2004;64(8): 885-912.

21. Anderson RU, Mobley D, Blank B, et al. Once daily controlled versus immediate release oxybutynin chloride for urge urinary incontinence: OROS Oxybutynin Study Group. J Urol. 1999;161(6):1809-1812.

22. Versi E, Apell R, Mobley D, Patton W, Saltzstein D. Dry mouth with conventional and controlled-release oxybutynin in urinary incontinence. The Ditropan XL Study Group. Obstet Gynecol. 2000;95:718.

23. MacDiarmid S, Anderson RU, Armstrong RB, Dmochowski RR. Efficacy and safety of extended release oxybutynin for the treatment of urge incontinence: an analysis of data from 3 flexible dosing studies. J Urol. 2005;174:1301-1305.

24. Gleason DM, Susset J, White C, Munoz DR, Sand PK. Evaluation of a new once-daily formulation of oxybutynin for the treatment of urinary urge incontinence. Ditropan XL Study Group. Urology. 1999; 54:420.

25. Appell RA, Sand P, Dmochowski R, et al. Prospective randomized controlled trial of extended-release oxybutynin chloride and tolterodine tartrate in the treatment of overactive bladder: results of the OBJECT Study. Mayo Clinic Proc. 2001;76(4):358-363.

26. Diokno AC, Appell RA, Sand PK, et al. Prospective, randomized double-blind study of the efficacy and tolerability of the extended-release formulations of oxybutynin and tolterodine for overactive bladder: Results of the OPERA Trial. Mayo Clin Proc. 2003;78:687-695.

27. Anderson RU, MacDiarmid S, Kell S. Effectiveness and tolerability of extended-release oxybutynin versus extended-release tolterodine in women with or without prior anticholinergic treatment for overactive bladder. Int Urogynecol J. 2006;17:502-511.

28. Kaplan SA, Roehrborn CG, Rovner ES, et al. Tolterodine and tamsulosin for treatment of men with lower urinary tract symptoms and overactive bladder: a randomized controlled trial. JAMA. 2006;296: 2319-2328.

29. Delafuente JC. Understanding and preventing drug interactions in elderly patients. Crit Rev Oncol Hematol. 2003;48(2):133-143.

30. Wagg AS, Cardozo L, Chapple C. Overactive bladder syndrome in older people. BJU. 1999;502-509.

31. Kay G, Crook T, Rekeda L, et al. Differential effects of the antimuscarinic agents darifenacin and oxybutynin ER on memory in older subjects. Eur Urol. 2006;50:317-326.

32. Lackner TE, Wyman JF, McCarthy TC, Monigold M, Davey C. Randomized, placebo-controlled trial of the cognitive effect, safety and tolerability of oral extended release oxybutynin in cognitively impaired nursing home residents with urge urinary incontinence. J Am Geriatr Soc. 2008;56:863-870.

33. Fick DM, Cooper JW, Wade WE, Waller JL, Maclean JR, Beers MH. Updating the Beers Criteria for Potentially Inappropriate Medication Use in Older Adults. Arch Intern Med. 2003;163:2716-2724.

34. Reinberg Y, Crocker J, Wolpert J, Vandersteen D. Therapeutic efficacy of extended release oxytubynin chloride and immediate release and long acting tolterodine tartrate in children with diurnal urinary incontinence. J Urol. 2003;169:317-319.

35. Mulcahy JJ, James HE, McRoberts JW. Oxybutynin chloride combined with intermittent clean catheterization in the treatment of myelomeningocele patients. J Urol. 1977;118:95.

36. Franco I, Horlowitz M, Grady R, et al. Efficacy and safety of oxybutynin in children with detrusor hyperreflexia secondary to neurogenic bladder dysfunction. J Urol. 2005;173:221-225. 
37. Hu TX, Wagner TH, Bentkover JD, LeBlanc K, Zhou SZ, Hunt T. Estimated economic costs of overactive bladder in the United States. Urology. 2003;61:1123-1128.

38. Boone TB, Kusek JW, Nyberg LM, et al. Treatment patterns and associated symptom improvement during six months of care for overactive bladder: a prospective, observational study. Clin Ther. 2002;24:397-408.

39. Hughes DA, Dubois D. Cost-effectiveness analysis of extended-release formulations of oxybutynin and tolterodine for the management of urge incontinence. Parmacoeconomics. 2004;22(16):1047-1059.

40. Perfetto EM, Subedi P, Jumadilova Z. Treatment of overactive bladder: a model comparing extended-release formulations of tolterodine and oxybutynin. Am J Managed Care. 2005;11(4):S150-S157.

41. Nitz NM, Jumandilova Z, Darkow T, Frytak JR, Bavendam T. Medical costs after initiation of drug treatment for overactive bladder: effects of selection bias on cost estimates. Am J Managed Care. 2005;11(4S): S130-S139.
42. Zinner N. Patient reported outcomes with once daily oxybutynin for urge incontinence. Obstet Gynecol. 1999;93(4 Suppl 1):29S.

43. Chancellor MB, Appell RA, Sathyan G, Gupta SK. A comparison of the effects of saliva output of oxybutynin chloride and tolterodine tartrate. Clin Ther. 2001;23(5):753-760.

44. Appell RA, Chancellor M, Zobrist RH, Thomas HM, Sanders SW. Pharmacokinetics, metabolism, and saliva output during transdermal and extended-release oral oxybutynin administration in healthy subjects. Mayo Clin Proc. 2003;78:696-702.

45. Franco I, Horowitza M, Grady R, et al. Efficacy and safety of oxybutynin in children with detrusor hyperreflexia secondary to neurogenic bladder dysfunction. J Urol. 2005;173(1):221-225.

\section{Publish your work in this journal}

Drug Design, Development and Therapy is an international, peerreviewed open-access journal that spans the spectrum of drug design and development through to clinical applications. Clinical outcomes, patient safety, and programs for the development and effective, safe, and sustained use of medicines are a feature of the journal, which has also been accepted for indexing on PubMed Central. The manuscript management system is completely online and includes a very quick and fair peer-review system, which is all easy to use. Visit http://www.dovepress.com/testimonials.php to read real quotes from published authors.

Submit your manuscript here: http://www.dovepress.com/drug-design-development-and-therapy-journal 